\title{
A SILENCIADA INCLUSÃO ESCOLAR DE PESSOAS COM DEFICIÊNCIA (AUTISMO) SOB UM OLHAR CULTURAL
}

\author{
Marília Gomes Ghizzi Godoy* \\ Aluana Xavier de Lima**
}

\begin{abstract}
Resumo
Por meio de textos acadêmicos tributários do estado da arte procuram-se aquilatar os sentidos de cidadania e emancipação cultural que acompanham as ações educativas com os alunos autistas nos meios escolares. Diante de uma condição humana própria e de uma situação de incompletude biológica pergunta-se como seguem as propostas integrativas e de equidade que vigoram no campo político da educação inclusiva. Configura-se uma abordagem documental que pauta os ganhos e as barreiras presentes no ensino, com relação aos sujeitos autistas. No recorte concernente ao sentido humano da escola e ao caráter transformador das iniciativas escolares e pedagógicas impõe-se uma vigilância e, às vezes, renúncia às dimensões representadas pelos diagnósticos terapêuticos. Nesse sentido, visamos entender como uma dimensão antropológica universalista que sustenta os direitos humanos das pessoas com deficiência é capaz de configurar uma eficácia simbólica expressiva de um contraste próprio frente ao exercício de políticas públicas de educação.
\end{abstract}

Palavras-chave: Autismo. Inclusão escolar. Modelo terapêutico. Estado da arte. Universalismo cultural.

\section{THE SILENCED SCHOOL INCLUSION OF PEOPLE WITH DISABILITIES (AUTISM) FROM A CULTURAL PERSPECTIVE}

\begin{abstract}
Through state-of-the-art of academic texts, we seek to assess the meanings of citizenship and cultural emancipation that accompany educational actions with autistic students in school environments. Faced with a human condition of its own and a situation of biological incompleteness, one wonders how the integrative and equity proposals in force in the political field of inclusive education follow. A documental approach is configured that guides the gains and barriers present in teaching, in relation to autistic subjects. With regard to the human sense of the school and the transformative character of school and pedagogical initiatives, vigilance is required and sometimes renunciation to the dimensions represented by therapeutic diagnostics. In this sense, we aim to understand how an universalist anthropological dimension that sustains human rights of people with disabilities is capable of configuring an expressive symbolic effectiveness of its own contrast to the exercise of public education policies.
\end{abstract}

Keywords: Autism. School inclusion. Therapeutic model. State of the art. Cultural universalism.

\footnotetext{
${ }^{*}$ Mestre em Antropologia Social (USP); doutora em Psicologia Social (PUC-SP); docente do Mestrado em Ciências Humanas da Universidade Santo Amaro (UNISA). E-mail: mgggodoy @ yahoo.com.br

${ }^{* *}$ Mestre em Ciências Humanas pela Universidade Santo Amaro (UNISA). E-mail: aluana.limawa@ gmail.com
} 


\section{Introdução}

Nos últimos decênios do século XX uma dinâmica internacional impõe-se no cenário mundial de uma crescente globalização, fundamentando-se uma nova ordem mundial. Originam-se valores que cruzam fronteiras com investimentos na área comercial, produtos culturais, ideias e pessoas, proliferação de redes transnacionais e controles em múltiplas localidades (HARVEY, 2004; CASTELLS, 1996). Os movimentos influenciam mudanças sociais, políticas e culturais, surge um acelerado processo de integração global no qual se inserem as propostas ligadas aos direitos de cidadania e inclusão social no contex to da educação pública e dos compromissos de Estados nacionais. Um intenso clima de mudanças impõe-se sob a égide de uma cultura "sábia" que requer uma militância própria de sujeitos comprometidos nas práticas educacionais interpretadas sob uma exigência dos direitos humanos e das visões culturais modernizadas assumidas no conceito de cidadania e participação social.

A hegemonia ocidental desses novos valores é representativa de uma Antropologia capaz de universalizar uma nova ordem de humanismo e de ética aplicável ao bem comum e ao ideal democrático. Essa realidade torna-se visível na cultura de inclusão expressiva das pessoas com deficiência $(\mathrm{PcD})^{1}$. A adesão entusiasta das escolas sob a égide de uma bandeira democrática projeta um campo de dinâmicas culturais capazes de retratar dimensões históricas carregadas de sentido diante do esforço que a nova era de valores humanos passou a exigir dos sujeitos envolvidos em situação de aprendizagem: aprendizes e profissionais do ensino. Nesse cenário, as novas teorias sobre educação, aprendizagem e inclusão social potencializam manifestações expressivas de liberdade e autonomia. A pessoa com deficiência conforma-se ao novo olhar enaltecedor de um campo de deveres legais legitimados historicamente nas conquistas jurídicas e que se reproduzem na esfera da educação.

Compreende-se que uma dimensão antropológica dos direitos humanos ganhou legitimidade como expressão de categorias universais que têm uma origem eurogênica e eurocêntrica (MARTINS, 2003). O modo de vida dos países ocidentais é legitimado nas transcrições normativas que operam como recursos emancipadores das políticas públicas educacionais.

A emergência dos sentidos de modernidade foi herdada desde a segunda metade do século XVIII, sob o impacto das ideias liberais dos iluministas, com a independência dos Estados Unidos (1776), a queda da monarquia na França (1786), com a Declaração Universal dos Direitos Humanos (1948), ratificados pela Conferência Mundial sobre os Direitos Humanos em 1992, em Viena. Nesse momento as várias organizações reafirmaram a convicção da universalidade dos direitos humanos e de sua indistinta aplicação às diversas tradições sociais, culturais e jurídicas (MARTINS, 2003, p. 9).

Uma ênfase na valorização do sujeito ocorre diante da consideração "todo ser humano", "toda pessoa", "ninguém será torturado", escravizado, com direitos a ter sua opinião política, religiosa e sexual. Os Direitos Humanos fundamentam-se como direitos básicos de todos os seres humanos, sendo eles de natureza civil, política, econômica, social e cultural.

\footnotetext{
${ }^{1}$ A nomenclatura PcD foi adotada a partir da Convenção sobre os Direitos da Pessoa com Deficiência das Nações Unidas, em 2006; desde então, convencionou-se que, ao se referir a essas pessoas, devemos utilizar esse termo.
} 
Compreendem direitos ao trabalho, à educação, à saúde, à moradia, à alimentação, direitos difusos e coletivos envolvendo a paz, o progresso e a autodeterminação dos povos. Dessa perspectiva institui-se um sentido humanista de engrandecimento do homem definindo uma "ética da nobreza humana". O antropocentrismo fundamentou-se na expressão "civilização humana" como um sinônimo de conquista da natureza e de enaltecimento das propriedades humanas exigindo que novos sentimentos se reconstruíssem na modernidade (CAMPOS; GODOY, 2018, p. 68ss.).

O modelo padronizado universalista, sua supremacia e dominância na criação de um campo jurídico próprio tornou-se alvo de reflexões que pontuam uma exigência de considerações particulares de origem moral que indicam a presença de dimensões locais como prioritárias no questionamento de sujeitos/cidadãos. Na atualidade, as consequências sociais, epistemológicas e existenciais passaram a questionar a unidade do mundo e dos valores representativos de um ideal democrático fundamentados numa visão positivista, acabada e material de evolução humana. O Indivíduo, a História e a Razão, como motores de um pensamento direcionaram-se às novas composições que marcam uma renovação dos saberes. No universo globalizado as perdas de raízes, de sentidos particulares e o anonimato que se projetam como uma expressão líquida da sociedade, exigem recentemente que as histórias humanas predominem, recompondo-se as noções fragmentadas de tempo e espaço (GIDDENS, 1991; BAUMAN, 2001; MAFFESOLI, 2004). O sobrepujamento do racional diante de uma sociedade puramente utilitária é compelido pelo caráter sensível com que a dimensão simbólica expressa a cultura (MAFFESOLI, 2004, p. 40s.).

\section{Metodologia}

O impacto dessas considerações permite entender como as políticas de inclusão ligadas ao autismo reproduzem temas consensuais quando defrontamos dados relacionados à natureza humana, ao caráter jurídico das políticas públicas com relação às $\mathrm{PcD}$ (autistas) e dados representativos das situações pedagógicas e de aprendizagem contidos em artigos que consideram o estado da arte na produção acadêmica.

As ações afirmativas elaboradas no âmbito das políticas de educação, fundamentadas na realidade escolar que cerca os alunos autistas se retratam nas produções acadêmicas relativas à sua inclusão no meio escolar. Um conhecimento científico contido nas obras abaixo selecionadas vigora no campo acadêmico a respeito do autismo em situação de educação pública e projetam um material significativo na compreensão pedagógica e educativa dos sujeitos autistas e dos novos tempos a serem enfrentados.

Esse tema tem envolvido numerosas reflexões. Nosso intuito consiste em compreender como o pensamento acadêmico discute os valores de cidadania, dignidade, emancipação de sujeitos autistas pela análise do estado da arte sobre esse tema. Os difíceis caminhos de inserção dessa minoria no universo de ensino-aprendizagem desafiam os investimentos educacionais implicando a exigência de conhecimentos sobre as principais tendências em situar a questão de um humanismo como uma ética que orienta o convívio com o diferente.

A predominância dos discursos acadêmicos nas sombras de um paradigma biológico, a incidência dos seus autores vinculados à área da saúde replica julgamentos parciais e rígidos comprometidos com um olhar dependente de uma visão empedernida sobre a realidade. Dessa 
ótica avaliou-se a emergência dos enfoques teóricos provenientes de implicações sociais e simbólicas capazes de entender não um corpo com impedimentos, mas uma pessoa em situação de coexistência. Os investimentos de natureza histórico-cultural abrem caminhos para uma leitura pedagógica não linear de desenvolvimento e aprendizagem que se afasta da linguagem behaviorista e unidimensional do ensino. O sujeito autista, sujeito expressivo de um epifenômeno na definição evolutiva do ser humano, refere-se como único, como sui generis na linguagem com que o conhecimento e sua expressiva leitura individualizada, o olhar da psicanálise, são capazes de vencer limites concebidos como intransponíveis, de racionalidade.

Considera-se que a sustentabilidade dos direitos humanos sob uma dimensão antropológica universalista reproduz a pessoa com deficiência (o autista) como uma personagem de uma eficácia simbólica expressiva de um contraste próprio, nos limites da deficiência. Uma perspectiva não antropocêntrica das propostas acadêmicas apresenta os desdobramentos da vida humana na realidade sociocultural da escola.

A produção de conhecimentos acadêmicos sobre a educação inclusiva e ações afirmativas no campo das $\mathrm{PcD}$, em particular dos alunos com diagnóstico de autismo, emerge como um material documental que abrange uma vasta expressão de investigações. O sentido de alteridade com que as experiências retratam situações da educação inclusiva apontam operações que reinventam saberes comprometidos política e ideologicamente com cidadãos em condições especiais. Os sentidos da diferença abrem um campo de ordenações que fundamentam a escola como uma instituição criadora de tradições. Conhecimento e cultura possibilitam a leitura do material documental compreendido pelo estado da arte sobre a inclusão de pessoas autistas.

O silêncio e a visibilidade, próprios de uma situação contrastante originam-se nos saberes compreendendo-se as ações pedagógicas, iniciativas de educação, como verdades que exigem um espaço próprio de reflexão. Expressa como estado da arte a produção científica contida em dissertações, teses e artigos que traduzem um recurso metodológico reconhecido institucionalmente, propicia uma visão de caráter descritivo com amplitude histórica e de ordenação social e política. Nesse trajeto testemunham-se conteúdos publicados em três artigos que têm como foco central o estado da arte sobre o autismo e a educação escolar.

1- Inclusão educacional de pessoas com Autismo no Brasil: uma revisão da literatura, de Débora Regina de Paula Nunes, Mariana Queiroz Orrico Azevedo e Carlos Schmidt. Revista Educação Especial, vol. 26, n. ${ }^{\circ}$ 47, set/dez 2013, pp. 557-572. Compreende teses e dissertações publicadas entre 2008-2012, nas bases de dados SCIELO, Birene e CAPES, com foco na escolarização de alunos com TEA, em classes comuns. Foram analisadas, de forma descritiva, vinte e oito produções entre 2008-2013 (NUNES; AZEVEDO; SCHMIDT, 2013, p. 559);

2- Estado da arte da produção sobre escolarização de crianças diagnosticadas com TEA, de Isabel de Barros Rodrigues e Carla Biancha Angelucci. Revista de Psicologia Escolar e Educacional, vol. 22, n 3, 2018, p. 545-555. O estudo mapeou a produção no banco de teses e dissertações da Scientific Eletronic Library Online (ScIELO) e a Biblioteca Virtual em Saúde (BVS-psi), considerou-se o processo de escolarização formal e as dimensões curriculares para alunos com TEA. Foram selecionadas oitenta e oito produções, das quais cinquenta e duas se retratam como específicas (relativas) do tema (RODRIGUES; ANGELUCCI, 2018, p. 549); 
3- Escolarização formal e dimensões curriculares para alunos com autismo: o estado da arte da produção acadêmica brasileira, de Anderson Jonas de Neves, Carolina de Santi Antonelli, Mariana Girotto Carvalho da Silva e Vera Lúcia Messias Fialho Capellini. Revista Educação em Revista, vol. 30, n. ${ }^{\circ}$ 2, abril-junho, 2014, p. 43-70, Belo Horizonte. Considerou-se a escolarização formal do aluno com autismo, relacionada às questões curriculares no período de janeiro de 1987 a dezembro de 2011 (NEVES et alii, 2014, p. 51ss.). Foram analisadas teses e dissertações no Banco de Teses e Dissertações da CAPES e selecionados quarenta e um trabalhos dos 157 inicialmente mapeados (NEVES et alii, 2014, p. 43, 51).

Mediante uma análise dos conteúdos contidos nesses artigos configura-se um conjunto de ideias e de problemas que dão sentido aos saberes escolares construídos sobre o aluno autista. O diálogo acadêmico impõe-se como uma identidade própria que se efetiva pelos recursos de racionalidade engajados criteriosamente no cenário educativo. Procura-se um centramento de dados como um olhar "o outro", o autista, o distante, que se encontra observado em uma realidade que o incorpora, dominando-se o diferente como objeto de um discurso polêmico, tangencial entre os mesmos e os outros. Mas, todos juntos nos propósitos de uma educação inclusiva.

O impacto representado pelos novos tempos, o desafio antropológico concernente aos valores científicos, tributários de uma ordem cultural mundial, defrontam-se com um cenário invasivo nas práticas escolares pela presença de expectativas da dignidade humana. O debate proposto segue um fio condutor decisivo que cruza os dados apresentados em uma perspectiva histórica em que um contraste marcante se origina como um elemento identitário da inclusão das PcD (autistas).

\section{A inclusão escolar das pessoas com deficiência (autismo) em uma cultura de direitos} humanos

A criação dos direitos humanos como pressupostos normativos otimistas de uma antropologia universal, atemporal e histórica projeta-se no campo educacional introduzindo leis como garantia de educação e cidadania para os deficientes. São leis que articulam moral e normativamente um tema de natureza qualitativa, que se orienta por experiências coletivas de reversão de injustiça, humilhações em uma tradição de preconceitos e segregações.

Os novos caminhos traçados pelo Estado Nacional ao gerirem os direitos humanos convencionam a modernidade para os deficientes, a perpetuação ideológica dos valores da cultura ocidental, antropocêntrica, antropomórfica. As leis cristalizadas na dimensão pública, legal e institucional retratam um espaço jurídico de autoafirmação do movimento emancipatório e de formação cidadã das $\mathrm{PcD}$. O quadro seguinte reúne os registros legais que expressam um movimento histórico de fundamentação normativa e jurídica da cidadania conquistada pelos deficientes diante de uma situação identitária derivada de critérios naturais de origem biológica. 


\section{Quadro 1}

\section{Registros legais e direitos educacionais de PcD (autismo)}

\begin{tabular}{|c|c|}
\hline $\begin{array}{l}\text { Decreto } 3.298 \text { que regulamenta a Lei } n^{\circ} \\
7.853 / 88\end{array}$ & $\begin{array}{l}\text { O decreto normatiza a Educação Especial } \\
\text { como uma modalidade transversal a todos } \\
\text { os níveis de ensino regular, da educação } \\
\text { infantil ao ensino superior. }\end{array}$ \\
\hline $\begin{array}{l}\text { Resolução CNE/CEB (Conselho Nacional } \\
\text { de Educação/Câmara de Educação Básica), } \\
n^{\circ} 2 / 20001 \text {, artigo } 2^{\circ}\end{array}$ & $\begin{array}{l}\text { A diretriz assegura educação de qualidade } \\
\text { e garantia de matrícula para todos os } \\
\text { estudantes com necessidades educacionais } \\
\text { especiais no ensino regular. }\end{array}$ \\
\hline $\begin{array}{l}\text { PNE (Plano Nacional de Educação), Lei n } \\
10.172 / 2001\end{array}$ & $\begin{array}{l}\text { A lei determina objetivos e metas para } \\
\text { melhoria da qualificação docente, } \\
\text { acessibilidade física, atendimento } \\
\text { educacional especializado, entre outras } \\
\text { intenções que mobilizem o apoio à } \\
\text { diversidade humana. }\end{array}$ \\
\hline Decreto $3.953 / 2001$ & $\begin{array}{l}\text { A norma reconhece a exclusão como } \\
\text { discriminação e elimina qualquer barreira } \\
\text { que impeça o acesso à escolarização. }\end{array}$ \\
\hline $\begin{array}{l}\text { Resolução CNE/CP (Conselho Nacional de } \\
\text { Educação/Conselho Pleno) n } 1 / 2002\end{array}$ & $\begin{array}{l}\text { O Conselho Nacional de Educação designa } \\
\text { organização curricular para ensino superior } \\
\text { e formação docente visando ao } \\
\text { conhecimento sobre especificidades dos } \\
\text { educandos. }\end{array}$ \\
\hline Decreto $\mathrm{n}^{\circ} 6.094 / 2007$ & $\begin{array}{l}\text { O decreto articula o PDE (Plano de } \\
\text { Desenvolvimento da Educação), } \\
\text { garantindo acessibilidade arquitetônica e } \\
\text { permanência dos estudantes com } \\
\text { deficiência no ensino regular e a } \\
\text { implantação de salas de recursos } \\
\text { multifuncionais. }\end{array}$ \\
\hline $\begin{array}{l}\text { Decreto Legislativo } \mathrm{n}^{\circ} 186 / 2008 \text { e Decreto } \\
\text { Executivo } \mathrm{n}^{\circ} 6.949 / 2009\end{array}$ & $\begin{array}{l}\text { Os estados ficam responsáveis por } \\
\text { proporcionar a educação inclusiva } \\
\text { garantindo o desenvolvimento social e } \\
\text { acadêmico do educando com deficiência. }\end{array}$ \\
\hline $\begin{array}{l}\text { Decreto } n^{\circ} 6.571 / 2008 \text {, incorporado pelo } \\
\text { Decreto } n^{\circ} 7.611 / 2011\end{array}$ & $\begin{array}{l}\text { O decreto dispõe de normas sobre } \\
\text { matrículas de alunos com deficiência no } \\
\text { FUNDEB (Fundo de Manutenção e } \\
\text { Desenvolvimento da Educação Básica) e } \\
\text { atribui diretrizes para o AEE (Atendimento } \\
\text { Educacional Especializado). }\end{array}$ \\
\hline Resolução CNE/CEB n 04/2009 & $\begin{array}{l}\mathrm{O} \text { Conselho Nacional de Educação } \\
\text { organiza normas específicas para o AEE }\end{array}$ \\
\hline
\end{tabular}




\begin{tabular}{|c|c|}
\hline & $\begin{array}{l}\text { (Atendimento Educacional Especializado) } \\
\text { e sua incorporação ao projeto político } \\
\text { pedagógico. }\end{array}$ \\
\hline Resolução CNE/CEB n 04/2010 & $\begin{array}{l}\text { A Resolução determina que as matrículas } \\
\text { dos estudantes com deficiência devem ser } \\
\text { efetivadas no ensino regular e AEE da rede } \\
\text { pública ou instituições equivalentes. }\end{array}$ \\
\hline Decreto $\mathrm{n}^{\circ} 7.084 / 2010$ & $\begin{array}{l}\text { O Ministério da Educação determina a } \\
\text { adoção de material didático designado para } \\
\text { a Educação Especial e professores das } \\
\text { escolas públicas de educação básica. }\end{array}$ \\
\hline Decreto $n^{\circ} 7.612 / 2011$ & $\begin{array}{l}\text { Institui-se o Plano Nacional dos Direitos } \\
\text { das Pessoas com Deficiência - Viver sem } \\
\text { limite. Com o intuito de articular políticas, } \\
\text { programas e ações que efetivem um } \\
\text { sistema educacional inclusivo. }\end{array}$ \\
\hline Lei $^{\circ} 12.764 / 2012$ & $\begin{array}{l}\text { A sanção consolida direitos baseados em } \\
\text { desenvolvimento, saúde, acesso à cultura, } \\
\text { ao lazer e emprego, bem como medidas de } \\
\text { punição para descumprimento de } \\
\text { efetivação de matrícula das pessoas com } \\
\text { TEA (Transtorno do Espectro Autista). }\end{array}$ \\
\hline PNE Lei $\mathrm{n}^{\circ} 13.005 / 2014$ & $\begin{array}{l}\text { O Plano Nacional de Educação determina, } \\
\text { no parágrafo } 1^{\circ} \text { inciso III, que Estados e } \\
\text { Municípios cuidem especificamente da } \\
\text { Educação Especial dentro do sistema de } \\
\text { educação inclusiva. }\end{array}$ \\
\hline 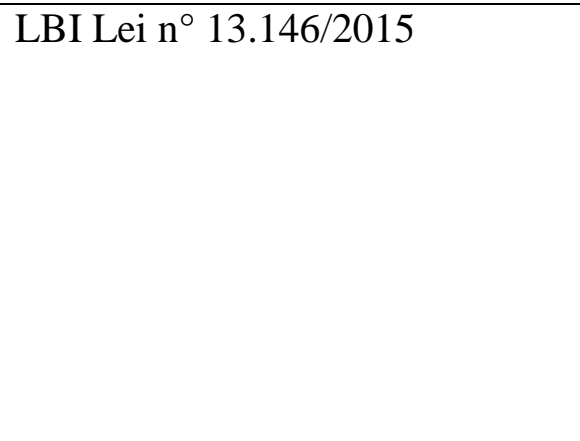 & $\begin{array}{l}\text { A promulgação institui a Lei Brasileira de } \\
\text { Inclusão, também denominada Estatuto da } \\
\text { Pessoa com Deficiência, assegura direitos } \\
\text { e condições de igualdade da pessoa com } \\
\text { deficiência visando à inclusão social e } \\
\text { cidadania, reafirmando diretos } \\
\text { fundamentais em todas as áreas de políticas } \\
\text { públicas. }\end{array}$ \\
\hline
\end{tabular}

Adaptado: Fonte http://portal.mec.gov.br/index.php?option=com.docman\&view=dowload\&alias=6726-marcospoliticos-legais\&itemid $=30192$

O impacto das leis tem um significado qualitativo pela sua dimensão autoafirmativa, "politicamente correta", ordenando-se como uma opção socialmente celebrada, que forma um material aparentemente inesgotável ao situar o novo campo relacionado à identidade do "outro". A bandeira do direito universalizado impõe-se no campo da deficiência em uma dimensão progressiva de configurar um relativismo cultural capaz de avançar sobre as resistências e acomodações que sempre vigoraram nas práticas tradicionais da educação com os $\mathrm{PcD}$, um 
campo de estigmas que sustentou ideologias difundidas nas seguintes expressões: deficientes, anormais, portadores de necessidades especiais, agora pessoas com direitos e condições políticas de autonomia, designadas pessoas com deficiência (PcD). Transitam-se espaços representativos de um foco exclusivo, concebido com ênfase à cultura do "outro". Enfocamos neste artigo os sujeitos e suas dimensões de conhecimento, palpáveis no meio acadêmico como um compromisso de formação educativa, como adiante enfatizaremos. Não se trata mais de sobressair o pensamento branco, masculino e ocidental, os que até há pouco eram "no máximo vítimas" passam a se representar como sujeitos das ações afirmativas.

Uma identidade social e cultural nasce como uma bandeira no reconhecimento e obediência ao "direito universal à diferença". Torna-se patente a emergência positivamente instaurada dos sucessos e fracassos oriundos da implantação da nova ordem de paz que necessita dialogar com as livres pertenças presentes na ordem moral, tradicional dos conhecimentos.

A escola é uma comunidade viva, ela produz sua própria cultura que exige os temas indiscutíveis do direito viabilizados na ética do discurso e introduzidas sobre a própria condição humana. Surge ela como um desafio a uma nova humanização que cultiva uma exorcização dos antigos valores comprometidos com a deficiência como uma anormalidade. O enfrentamento de problemas e a construção dos ideais emancipatórios seguem responsáveis pela viabilização da libertação dos sujeitos como "outros", os que precisam ser incluídos. Diante de um momento de atuação e criação efetiva de direitos humanos, este artigo segue, como questão central, uma alteridade ameaçada ao "silêncio", ao "isolamento".

Segundo a Lei $\mathrm{n}^{\circ}$ 12.764, de 2012, o autismo, como expressão definida para as pessoas com TEA, define:

[...] é considerada pessoa com transtorno do espectro autista aquela portadora de síndrome clínica caracterizada na forma dos seguintes incisos I ou II: Ideficiência persistente e clinicamente significativa da comunicação e da interação sociais, manifestada por deficiência marcada de comunicação verbal e não verbal usada para interação social; ausência de reciprocidade social; falência em desenvolver e manter relações apropriadas ao seu nível de desenvolvimento; II- padrões restritivos e repetitivos de comportamentos motores ou verbais estereotipados ou por comportamentos sensoriais incomuns; excessiva aderência a rotinas e padrões de comportamento ritualizados; interesses restritos e fixos (BRASIL, 2012).

\section{O discurso emancipador da educação}

Uma visão consolidada de registros fundamenta-se no valor humano da educação construída historicamente pela civilização e que se legitimou como fundamental nas instituições.

A educação é concebida como um conjunto de recursos, estratégias, metodologias, conteúdos e recursos humanos que, ao estarem organizados e dispostos nas diversas instâncias do universo escolar, devem produzir valores, condutas e processos que visem à valorização e ao respeito à diversidade humana, à apropriação de conhecimentos, à formação cidadã e aos novos 
olhares e práticas sobre o ensinar e o aprender (LEITE; BORELLI; MARTINS, 2013, p. 44 apud NEVES et alii, 2014, p.44).

Compreende-se que o acesso, a permanência e o êxito de todos os alunos, sem distinções, conferem os sentidos ideais de cidadania e democracia implícitos nas ações educacionais.

O caráter construtivo das políticas públicas e das ações governamentais por meio da Política Nacional de Educação Especial na Perspectiva da Educação Inclusiva (2008) que determinou a inclusão das $\mathrm{PcD}$, do autista, na rede regular de ensino, possibilitaram um crescimento no número de educandos com autismo. Conforme dados do MEC, em 2006 havia 2.204 alunos com esse diagnóstico inseridos nas escolas regulares, em 2012 o número aumentou para 25.624 (NUNES; AZEVEDO; SCHMIDT, 2013, p. 559), o que confere visibilidade à lei Berenice Piana, ou Lei do Autismo, lei 12.764 (BRASIL, 2011). ${ }^{2}$

Entre 2003 e 2015 constatou-se um crescimento de 425\% de matrículas em classes comuns, de pessoas identificadas como público alvo da Educação Especial na educação básica (RODRIGUES; ANGELUCCI, 2018, p. 547).

Pode-se crer que a inserção de um público diferenciado incorporou-se aos novos limites dos tempos, com a inclusão do aluno autista. Tornou-se visível a encenação da ação política, cultural, social e pedagógica possibilitando um ambiente de aprendizagem e de convívio coletivo (BRASIL, 2007). A nova visão segue com otimismo no sucesso da proposta da escola inclusiva. Tornou-se unânime o reconhecimento das "crianças com TEA, oportunizando a interação entre pares e contribuindo para o desenvolvimento de novas aprendizagens e comportamentos" (NUNES; AZEVEDO; SCHMIDT, 2013, p. 558).

Compreende-se, contudo, que a viabilidade dos valores emancipatórios é questionada quando consideramos que as práticas contraditórias e segregadoras são registradas no contexto da inclusão, suscitando-se manifestações com relação à manutenção de escola especial (NEVES et alii, 2018, p. 539-540). Afirma-se que, ao mesmo tempo em que os alunos autistas são "incluídos", barreiras dificultam o processo de compartilhamento e aprendizagem, reforçandose a insegurança dos pais (NUNES; AZEVEDO; SCHMIDT, 2013, p. 530). A orientação dos sistemas de ensino de garantir o aprendizado com base nas necessidades do educando pela determinação do Atendimento Educacional Especializado (AEE), conforme os decretos 6571/2008 e 7611/2011, não pode ser concebido como reforço escolar, mas como uma possibilidade de atendimento mediante recursos didáticos e pedagógicos (BRASIL, 2010).

Emergem dados sobre as dificuldades de acompanhamento dos conteúdos pedagógicos pelos alunos autistas. Os resultados indicam que $90 \%$ dos educandos do ensino fundamental não acompanhavam os conteúdos pedagógicos, no $1^{\circ}, 2^{\circ}$ e $3^{\circ}$ ciclos do ensino fundamental, uma parcela significativa não sabia ler, escrever ou fazer conta (GOMES; MENDES, 2010 apud NUNES; AZEVEDO; SCHMIDT, 2013, p. 542). Esses dados seguem quando se constatam as dificuldades no sucesso de uma realização formal de escolaridade. Testemunha-se o atraente ganho social que a presença do aluno autista representa no convívio e sociabilidade escolar.

\footnotetext{
${ }^{2}$ Esta lei resultou de um movimento de militância realizado por ativistas e familiares de pessoas autistas em dimensão nacional. Berenice Piana, diante do diagnóstico de seu filho Dayan, com seis anos, liderou o movimento junto com outras mães em um momento de invisibilidade desse diagnóstico. A batalha representou reivindicações e demandas por direitos multintersetoriais. A lei foi promulgada depois de dez anos de movimento (LIMA, 2020, p. 36s.).
} 
Contudo, é predominante a constatação de que "os métodos de ensino utilizados pelos professores produzem limitado impacto na aprendizagem dos educandos com autismo (NUNES; AZEVEDO; SCHMIDT, 2013, p. 562).

O presente histórico e a cultura de uma nova Era para as PcD retratam-se nas produções e iniciativas acadêmicas de ensino que expressam um movimento tributário das universidades públicas as quais criaram compromissos didáticos e pedagógicos no cenário da educação inclusiva. Pontua-se uma concentração das pesquisas realizadas no âmbito das instituições públicas com uma incidência no âmbito federal (RODRIGUES; ANGELUCCI, 2018, p. 549). Destacam-se a Universidade Federal de São Carlos, a do Rio Grande do Sul e a Universidade de São Paulo. Com predominância, as produções acadêmicas estão inseridas em programas de Pós-graduação em Educação (em linhas de pesquisa em Educação Especial ou Educação Inclusiva). Os pesquisadores revelam-se por pertencerem a um público formado "predominantemente por pessoas com formação inicial na área da Saúde, que realizaram pósgraduação em Educação, em linhas de pesquisa em Educação especial”, 93,75\% das produções são posteriores a 2008 (RODRIGUES; ANGELUCCI, 2018, p. 549-550).

\section{A presença do modelo biológico}

A perspectiva de reabilitação em saúde pressupõe um paradigma de compreensão que acompanha as crianças diagnosticadas com TEA, situando-as próximas da clínica de normalização. O saber biomédico é considerado prioritário como exigência para o ensino e as iniciativas escolares aproximam-se das antigas práticas de Educação Especial. Com o foco na concepção biológica, as produções acadêmicas projetam profissionais com formação inicial na área da saúde, norteada pelo diagnóstico de TEA no DSM. Evidencia-se a discussão do lugar que o autismo pressupõe com base nos manuais de Psiquiatria. Pontuando-se distinções sintomatológicas, define-se uma epistemologia do conhecimento comprometida mais com os aspectos da maturação do sistema nervoso (fatores de motricidade, competências sensoriais, comunicação e linguagem) em uma perspectiva biologizante que enfatiza a relação entre saúde e educação.

A ênfase nesse princípio construiu uma fronteira como uma margem para um padrão de desempenho e conhecimento: o campo da normalidade. $\mathrm{O}$ alvo dos diagnósticos configurou-se na noção de "debilidade intelectual", exigindo-se que educar seria normalizar (RODRIGUES; ANGELUCCI, 2018, p. 546).

A ausência de habilidades, atenção deficitária, próprias desse enfoque resultam também em uma ausência de desejos de interação e comunicação (BRANDÃO, 2009, p. 17 apud RODRIGUES; ANGELUCCI, 2018, p. 551). O foco dos trabalhos nessa área indica que fazer ciência é plasmar-se ao saber médico, evidenciando-se a predominância desse enfoque nos bancos de dados (RODRIGUES; ANGELUCCI, 2018, p. 551).

Com a meta em resultados adaptativos e de treinamentos para o desenvolvimento de "competências" impõe-se o apoio à interdisciplinaridade e à multidisciplinaridade como diretrizes a caminho de uma funcionalidade em que as intervenções forem adequadas.

Nesse sentido, entendemos que a noção de competências na relação ensinoaprendizagem se relaciona intimamente a uma tendência de padronização que 
entende no treinamento a maneira de preparar essas crianças para desempenhar adequadamente as habilidades sociais exigidas pela escola. $\mathrm{Na}$ tentativa de compreender e julgar quais elementos seriam essenciais nesse percurso escolar, alguns pesquisadores observam o desenvolvimento dos alunos a partir de intervenções pontuais ou da comparação com outros alunos (RODRIGUES; ANGELUCCI, 2018, p. 551).

\section{Ensino e aprendizagem: o modelo social}

A linguagem acadêmica, centralizada hegemonicamente no modelo biomédico e no contexto de restrições de habilidades e suas intervenções curativas de reabilitação teve grande influência nas políticas de educação e saúde para os deficientes (FARIAS; BUCHALLA; 2005, p. 192 apud DINIZ; BARBOSA; SANTOS, 2009, p. 71). Nos anos 60 as reflexões sobre natureza e cultura exigiram um deslocamento da concepção do ser humano compelida de um "estado bruto natural". A dimensão simbólica tornou-se o motor de uma nova dimensão sobre o corpo em uma situação social de representação e de valor. Com isso, uma nova forma de domínio científico emerge no campo da deficiência pelo deslocamento da questão dos impedimentos físicos, intelectuais e sensoriais, para um discurso centralizado em um desafio da normalidade, em semelhança com os estudos sobre velhice, "uma pessoa com deficiência não é simplesmente um corpo com impedimentos, mas uma pessoa com impedimentos vivendo em um ambiente com barreiras" (DINIZ; BARBOSA; SANTOS, 2009, p. 72).

A questão chave exige a compreensão particular das experiências culturais da deficiência que está representada na própria definição da pessoa com deficiência (PcD). Nesse sentido a cultura de direitos humanos seguiu novos caminhos para a construção dos ideais democráticos e de cidadania explorados no universo social. Configurou-se um espaço de domínios teóricos derivado da perspectiva histórico-cultural, concepção com o foco fundamental no desenvolvimento escolar pela mediação de valores simbólicos na relação alunoprofessor (RODRIGUES; ANGELUCCI, 2018, p. 551). ${ }^{3}$

Uma parte da produção acadêmica nessa condição retrata um sentido ambivalente em sua dimensão discursiva, não rompendo os comprometimentos com uma visão naturalizada da experiência educacional, pela importância de seus efeitos na educação. Essa via, com foco comportamental, denuncia a exigência da atuação dos professores no contexto da escolaridade. Os autores investem nas diferenças individuais exigindo recursos e metodologias. As possibilidades de ensino incidem nas barreiras que vigoram no meio pedagógico as quais têm origem na própria instituição escolar (RODRIGUES; ANGELUCCI, 2018, p. 552). O espaço da aprendizagem gerado com este enfoque pode anunciar ganhos de um contexto interativo sob o controle pedagógico institucional.

E, por isso, é nessa categoria que observamos os poucos trabalhos que relatam progressos acadêmicos entre os sujeitos participantes da pesquisa, ou ainda a conclusão de que o sucesso acadêmico não é visto porque a inclusão escolar

\footnotetext{
3 A teoria histórico-cultural, conforme Vygotsky, considera o caráter dinâmico e incompleto do homem, constituindo-se o processo de hominização continuamente no ciclo de vida. Impõe-se que os sujeitos estão em relação social com o mundo e a comunicação coletiva origina-se por meio de ações mediadoras (ORRÚ, 2010, p. 7 apud LIMA, 2019, p. 48).
} 
não é feita adequadamente (SILVA, 2011 apud RODRIGUES; ANGELUCCI, 2018, p. 552).

Salienta-se nos estudos realizados uma evidência da pouca relação das concepções teóricas dos professores e suas práticas “em geral, prevaleciam concepções de desenvolvimento, aportadas na abordagem histórico-cultural e o uso de estratégias de ensino derivadas do modelo behaviorista" (NUNES; AZEVEDO; SCHMIDT, 2013, p. 562).

$\mathrm{O}$ tema relacionado à necessidade de preparo e formação especializada dos docentes e dos auxiliares de ensino mostra-se com evidência como uma expressão desafiadora no universo pesquisado. O imperativo constante dessa ausência combina-se com os temas das exigências de estratégias de ensino e confecção de relatórios psicopedagógicos de avaliação. Na amplitude e complexidade das experiências acadêmicas constantemente observa-se a tradicional presença de preconceitos estereótipos que enfatizam as barreiras do ensino. Os profissionais e agentes diversos da instituição escolar originam-se como sujeitos inseridos na longa história de conflitos, em reforço de uma segregação dos alunos autistas. O questionamento sobre o modo de conhecer o aluno não pode retirar o protagonismo do professor, constantemente aprisionado nas barreiras do discurso especializado de áreas da Educação Especial (Psicologia, Fonoaudiologia, Medicina etc.) (RODRIGUES; ANGELUCCI, 2018, p. 552).

No contexto escolar o estudo de Neves preconiza a defesa da perspectiva da educação inclusiva por meio do currículo como forma de criação de soluções específicas aos alunos autistas, proposta liderada por vários autores (ZANATA, 2004; LEITE; MARTINS, 2010; GARRIDO; GIL; MAJÓN, 1997 apud NEVES et alii, 2018). O caminho curricular como possibilidade para a eficácia de planejamento pedagógico é visível em $21,57 \%$ do total dos estudos relativos realizados por esses autores, configurando-se os sentidos de flexibilização, adequação e adaptação curricular (NEVES et alii, 2018, p. 46).

$\mathrm{O}$ enigma presente nos meios escolares retém nossa atenção diante de uma experiência de pesquisa em que o pesquisador realizou um estudo de caso em uma Escola Parque. Constatou-se uma dimensão de ganhos nas tarefas em grupo com uso compartilhado de material didático. Esse olhar pode seguir adiante na aprendizagem em que a construção coletiva originou-se longe das exigências de um conteúdo formal, como a aprendizagem e escrita (BRANDÃO, 2009 apud NUNES; AZEVEDO; SCHMIDT, 2013, p. 565).

\section{A presença do sujeito autista}

O caráter contrastante da inclusão dos sujeitos com autismo que se constrói por trajetos ambíguos e críticos diante da educação e escolaridade incide no quadro desfavorável dos registros intrínsecos ao seu comportamento social. O argumento nesse sentido assinala que:

As dificuldades na interação interpessoal podem manifestar-se como isolamento, comportamento social impróprio, pobre contato visual, dificuldade em participar de atividades em grupo, indiferença afetiva, ou demonstrações impróprias de afeto e falta de empatia (GADIA; TUCHMAN; ROTTA, 2004 apud NEVES et alii, 2014, p. 49).

Em continuidade a essas constatações crescem as evidencias de defasagens no universo da comunicação. Registra-se a presença de desvios semânticos e pragmáticos que ocorrem na 
área da linguagem, rigidez de pensamento e compreensão, reduzida abstração, déficits intelectuais, comportamentos ritualísticos e obsessivos que marcam a área cognitiva (SANTO; COELHO, 2006 apud NEVES et alii, 2014, p. 49). Essas manifestações acentuam a exigência da individualização no tratamento pedagógico dos sujeitos (NEVES et alii, 2014, p. 48; RODRIGUES; ANGELUCCI, 2018, p. 553; NUNES; AZEVEDO; SCHMIDT, 2013, p. 566).

Configura-se uma dimensão humana de incompletude com riscos de um afastamento na construção do sujeito. Os textos analisados reproduzem as defasagens aliadas às frequentes barreiras que se constroem no ambiente escolar, quando encarado sob a égide de um ensino regular e normatizado distante de um tratamento individualizado. Com base nessas considerações é que se coloca a grande questão dos registros que frequentemente pontuam a presença de imagens caricaturais, o caráter representativo da síndrome pelo sentido infantilizado da comunicação. A busca dos caminhos tende, portanto, a seguir de forma não linear, impondo-se os desafios às manifestações de coesão social. Um entusiasmo generalizado pode ser visualizado diante das possibilidades de flexibilidades do currículo escolar pela ordenação de um currículo adaptado, solução que vem representando o grande investimento dos recursos pedagógicos.

A favor de um fortalecimento da experiência subjetiva e da formação de laços sociais desenvolveu-se o movimento teórico ligado à Psicanálise. Propondo-se uma tentativa de relativização das limitações terapêuticas e caráter naturalizado dos padrões acertados pelos manuais médicos, este enfoque segue também distante dos discursos acadêmicos especializados, uma vez que estes consideram a priori critérios definidores da aprendizagem (ARAUJO, 2011 apud RODRIGUES; ANGELUCCI, 2018, p. 552).

Ao serem isoladas as influências mencionadas, a visão psicanalítica investe nos vínculos sociais com o foco na tendência "saber fazer" dos alunos autistas. Incorporando-se os sofrimentos que os afetam, são dimensionados investimentos afetivos reversivos das dificuldades e dos limites de aprendizagem.

\section{Considerações Finais}

O conhecimento científico sobre o autismo e a inclusão escolar projetou-se no estudo do estado da arte desse tema abrigando uma situação própria de caráter humanista e cultural, pressuposto por uma antropologia universal ligada aos direitos humanos e à projeção da modernidade.

Uma ênfase na situação contrastante dos autistas, como $\mathrm{PcD}$, construiu-se nos significados acadêmicos marcando um espaço de valor diante de suas singularidades, uma condição biológica expressiva da própria natureza humana em seus universos diversificados de representação.

O apelo na articulação de uma concepção histórica da Inclusão Escolar revela-se no sentido unânime com que se reconhece a importância de vencer as barreiras que se impõem no meio escolar. A ênfase nas dificuldades "os autistas não conseguem" segue o trânsito dos temas que transcendem o imaginário coletivo que vem sendo cultivado: "escola para todos", "a barreira não está na criança”, "o diagnóstico médico não é normativo para a educação".

O objetivo do mapeamento das considerações acadêmicas balizadas segundo a realidade escolar aponta para um estado de direito que incide culturalmente nas dinâmicas de mudança e 
correção na esperança de que as questões formais pontuadas (adaptações na área curricular, análises psicopedagógicas, planejamento, formação específica do professor e do auxiliar pedagógico) não representam um prontuário de acusações que informam as situações da aprendizagem, mas uma proposta, antes de mais nada, de cumprir e cultivar o valor simbólico que constrói um caminho de cidadania e de direito. Dessa forma, presume-se que o caráter unitário do saber científico se reitera na reafirmação das condições de sobrevivência de sujeitos sob pressões expressivas de sua própria natureza, concebendo-se a escola como um experimento coletivo da vida humana.

A presença ostensiva de uma tradição dos saberes acadêmicos fundamentados biologicamente, naturalizando-se a deficiência como um suporte dominante dos sintomas, a corporeidade estigmatizada, segue diante dos novos impactos onde crescem os discursos que se valem do ideário emancipador e educativo da instituição escolar.

\section{Bibliografia}

BAUMAN, Z. Modernidade Líquida. São Paulo: Companhia das Letras, 2001.

BRASIL. Conselho Nacional de Educação. Resolução n ${ }^{\circ}$ 7, de 14 dez. 2010, Brasília: Distrito Federal.

BRASIL. Decreto $n^{\circ}$ 6.571, de 17 de setembro de 2008. Brasília: Distrito Federal.

BRASIL. Decreto $n^{\circ}$ 7.611, de 17 nov. 2011. Brasília: Distrito Federal.

BRASIL. Lei $n^{\circ}$ 12.764: Política Nacional de Direitos da Pessoa com transtorno do Espectro Autista, de 27 dez. 2012. Brasília: Distrito Federal.

BRASIL. Pró-Letramento. Programa de Formação Continuada de Professores das Séries Iniciais do Ensino Fundamental. Brasília: SEE, 2007, Brasília: Distrito Federal.

CAMPOS, A. L. A.; GODOY, M. G. G. Concepções ideológicas sobre a natureza e a ciência. Revista do Direito, vol. 2, n 55, Santa Cruz do Sul: Porto Alegre, mai./ago. 2018, p. 58-75.

CAPELLINI, V. L. M. F. Avaliação das possibilidades do ensino colaborativo no processo de inclusão escolar do aluno com deficiência mental. 2004. 302f. Tese (Doutorado no Centro de Educação e Ciências Humanas) - Programa de Pós-graduação em Educação Especial, Universidade Federal de São Carlos, São Carlos.

CASTELLS, M. A sociedade em rede. São Paulo: Paz e Terra, 1996. vol. 1.

DINIZ, D.; BARBOSA, L.; SANTOS, W. R. Deficiência, Direitos Humanos e Justiça. Revista Internacional de Direitos Humanos, vol. 6, n 11, São Paulo, dez. 2009. p. 65-77.

FINELLI, L. A. C.; ABREU, B. M. D.; CARVALHO, M. A. R. Autismo: percepção dos pais sobre o desenvolvimento. Fortaleza, Revista Humanidades, v. 6, ${ }^{\circ}$ 1, fev. 2017, p. 77-85.

GIDDENS, A. As consequências da modernidade. São Paulo: UNESP, 1991.

HARVEY, D. O novo imperialismo. São Paulo: Loyola, 2004. 
LEITE, L. P.; BORELli, T. M.; MARTINS, S. F. O. Currículo e deficiência: análise de publicações brasileiras no cenário da educação inclusiva. Educação em Revista, Belo Horizonte, v. 29, n. 1, 2013.

LIMA, A. X. Desafios da inclusão: alfabetização de alunos com transtorno do espectro autista (TEA). 2020. 147f. Dissertação (Mestrado no Programa Interdisciplinar em Ciências Humanas) - Universidade Santo Amaro, São Paulo.

MAFFESOLI, M. Notas sobre a pós modernidade - o lugar faz o elo. São Paulo: Atlântica, 2004.

MARTINS, E. R. Os direitos humanos em perspectiva histórica: universalismo, particularismo e a questão do exílio virtual. In: BOUCAULT, C. E. A.; MALATIN, T.. Políticas Migratórias: Fronteiras dos Direitos Humanos no Século XXI. Rio de Janeiro: Renovar, 2003.

MELO, A. G. Por uma abordagem antropológica da deficiência: pessoa, corpo e subjetividade. 2009. 86f. Monografia de conclusão de Curso (Graduação em Ciências Sociais) - Universidade Federal de Santa Catarina, Florianópolis-SC.

NEVES, A. J.; ANTONELLI, C. S.; SILVA, M. G. C.; CAPELLINI, V. L. M. F. Escolarização formal e dimensões curriculares para alunos com autismo: o Estado da Arte da produção acadêmica brasileira. Educação em Revista, v. 30, n. 2, Faculdade de Educação da Universidade Federal de Minas Gerais, Minas Gerais, abr./jun. 2014, p. 43-70.

NUNES, D. R. P.; AZEVEDO, M. Q. O.; SCHMIDT, C. Inclusão educacional de pessoas com autismo no Brasil: uma revisão da literatura. Revista Educação Especial, v. 26, n. 47, Santa Maria - RS, set/dez. 2013, p. 557-572.

RODRIGUES, I. B.; ANGELUCCI, C. B. Estado da arte da produção sobre escolarização de crianças diagnosticadas com TEA. Revista Psicologia Escolar e Educacional, v. 22, n. 3, São Paulo, set./dez. 2018, p. 545-555.

SIQUEIRA, H. S. G.; PEREIRA, M. A. O sentido da autonomia no processo de globalização. Educação em Revista, Santa Maria, RS, v. 22, n. 2, 1998, p. 70-89. 